Alina A. Korbut, Ph. D. in Pedagogy, Associate Professor, Belarusian State University of Culture and Arts (Minsk, Belarus) buk@buk.by

\title{
PRESERVATION OF PEOPLE'S CULTURE IS THE KEY TASK OF BELARUSIAN STATE UNIVERSITY OF CULTURE AND ARTS
}

\begin{abstract}
The paper names the primary areas of work of academic staff of Belarusian State University of Culture and Arts (Minsk, Belorussia) in research, preservation, popularization of people's culture and traditional art. The author reviews the experience of getting students acquainting with samples of song, musical, dance, game folklore of peoples of Belarus in educational process and practical-focused training in the major institutions of culture in the country. The key directions of informational, research work runs by departments of the University in ethnography of peoples dwelled in the today's Belorussia are listed. Also, the author describes the experience of inclusion of folklore materials into lists of stage productions of performance groups of Belarusian State University of Culture and Arts.

Keywords: Belarussian folklore, traditional culture, people's song culture, people's dance culture, people's arts and crafts, revitalization, Belarusian State University of Culture and Arts, educational-bringing-up process.
\end{abstract}

\section{References}

1. Ay̆tentychny fal'klor: prablemy zahavannya, vyvuchennya, usprymannya: (pamyaci antrapolaga Zinaidy Mazhejki) [Authentic Folklore: Problems of Preservation, Research, And Perception (In Memory of Anthropologist Zinaida Mozheiko))]. Minsk, 2015. 259 p. [In Belaruss.].

2. Kul'tura Belarusi: realii sovremennosti $[\mathrm{Cu}-$ ture of Belarus: Modernity]. Minsk, 2018. 257 p. [In Russ.].

3. Kul'tura. Nauka. Tvorchestvo [Culture. Science, Creativity]. Minsk, 2018. 603 p. [In Russ.].

4. Lobachevskaya O.A. Belorusskij narodnyj tekstil': hudozhestvennye osnovy, vzaimosvyazi, novacii [Belorussian Folk Textile: Artistic Basis, Interrelations, Innovations]. Minsk, 2013. 527 p. [In Russ.].

5. Sokolova O. M. Minskij tekst: problematika kul'turnoj pamyati stolichnogo goroda $\mathrm{v}$ usloviyah civilizacionnogo pomezh'ya [Minsk Text: Problematics of Cultural Memory of A Capital in Inter-Civilizational Areas]. Minsk, 2017. 417 p. [In Russ.].

УДК (571.1/.5):008(4)

DOI: 10.32340/2514-772X-2019-1-77-82
6. Cen' straly: kul'turnyya i verbal'nyya kody tradycyi [Shadow of an Arrow: Cultural and Verbal Codes of A Tradition]. Minsk, 2018. 190 p. [In Belaruss.].

7. Churko Yu. M. Belorusskij horeograficheskij fol'klor: tradicii $i$ sovremennost' [Belarusian Choreographic Folklore: Traditions And Modernity]. Minsk, 2016. 386 p. [In Russ.].

8. Shaura R. F. Razviccyo narodnaga vyyay̆lenchaga i dekaratyy̆naga mastactva Belarusi y̆ drugoj palove HIX - pachatku XX st. [Development of People's Fine And Decorative Arts in Belarus of The Second Half of the $19^{\text {th }}-$ the beginning of the $20^{\text {th }}$ Centuries] Minsk, 2006. 384 p. [In Belaruss.].

9. Yakonyuk N. P. Narodno-instrumental'naya muzykal'naya kul'tura pis'mennoj tradicii v Belarusi: opyt sistemnogo analiza [People's Instrumental Music Culture of writing Culture in Belorussia: An Experience of Complex Analisys]. Minsk, 2001. 269 p. [In Russ.].

\section{Д. Ланца, кандидат культурологии, Туринский университет (Турин, Италия) dnl.lanza@gmail.com}

\section{ОБРАЗЫ СИБИРИ В КУЛЬТУРЕ ЕВРОПЫ}

Аннотация. Проанализированы представления о Сибири в европейской культуре XVIII-XXI вв., охарактеризованы ключевые политико-идеологические и экономические факторы, оказавшие влияние на их оформление и закрепление в культурном сознании исторического и современного европейца. Приводятся малоизвестные в

о Сибири, культурные стереотипы о Сибири, воспоминания иностранных путешественников о Сибири, европейская печать о Сибири, Сибирь как культурный «бренд» России, массовая культура, массовое сознание, Сибирь, Алтай, Европа, европейская культура, образ в отечественной историографии фрагменты мемуарной и этнографической литературы, опубликованной иностранцами, в разное время лично посещавшими сибирские земли. Изложен авторский взгляд на генезис истинных и ложных историко-культурных и географических стереотипов о Сибири.

Ключевые слова: представления европейцев о культуре, культурный стереотип. 
Перед непосредственным рассмотрением заявленной темы необходимо сделать некоторое уточнение относительно того, что статья посвящена, в первую очередь, стереотипам и образам, бытующим относительно Сибири в пространстве культуры Европы. В данном случае речь идет не о всей культуре, а о ее массовом уровне, имеющем достаточно поверхностный, однако устойчивый и максимально распространенный характер.

Сразу отметим, что среди иностранцев, которые бывали в Сибири, есть выдающиеся географы, путешественники, исследователи, многие из которых посвящали свою жизнь России и Сибири и деятельность которых так или иначе связана с Алтаем. Достаточно вспомнить имена уроженца Саксонии, известного естествоиспытателя, врача, географа, исследователя Алтая, члена-корреспондента Российской Академии наук Фридриха Августа фон Геблера; немецкого географа, натуралиста и путешественника Александра фон Гумбольдта; выходца из Саксонии, горного специалиста Карла Крестьяновича Бера и многих других уроженцев Европы. Кроме того, в самой культуре Европы найдется много ее представителей, имеющих достаточно точные и адекватные представления о Сибири и России в целом. Тем не менее, на массовом уровне дела обстоят достаточно противоречиво.

Вопрос представлений европейцев о Сибири как историко-культурной и природной территории на массовом уровне является интересным, сложным и многоаспектным.

Основу рассматриваемой проблемы составляет то, что общие представления о Сибири, имея тесную сопряженность с распространенными стереотипами и поверхностными образами, которые, однажды возникнув и закрепившись в пространстве массовой культуры, устойчиво тиражируются и в наши дни. На данное обстоятельство влияет множество факторов-в первую очередь, политикоидеологический и экономический, - факторы, тесно связанные с геополитическим взаимодействием цивилизаций, включая их противостояние и конкуренцию на мировой арене. С другой стороны образы Сибири, фигурируя в культуре Европы, могут создаваться и транслироваться на более приземленном уровне, в качестве общих мировоззренческих представлений о реальности другой культуры. Оба уровня находятся в тесном взаимодействии и влияют друг на друга, сохраняя свои особенности и в наши дни. Тем не менее, первый уровень, наряду с вполне адекватными приме- рами понимания другой историко-культурной территории, до сих пор культивирует достаточно политизированные и порой гротескные образы Сибири; второй носит менее противоречивый характер, однако также не лишен предрассудков и упрощений. Соответственно, в настоящей статье дается обзор как политизированных образов рассматриваемого региона России, так и его отражений в массовом сознании европейского обывателя, лишенного явного политико-экономического оттенка.

Итак, стереотипизированные образы России в целом и Сибири в частности стали распространяться в Европе еще в конце XVII века при сильном влиянии геополитического фактора, выраженного в противостоянии и конкуренции европейских государств. Показательно в данном случае мнение современного исследователя Рональда Лова, указывающего на заинтересованность России в снижении степени проникновения иностранцев в Сибирь на фоне растущей колониальной экспансии европейских стран $[6$, с. 86]. Отмеченная закрытость создала почву для возникновения стереотипов и предрассудков о данном регионе в других странах. Также Рональд Лов приводит воспоминания французского иезуита Филиппа Аврелия, посетившего Сибирь в конце XVII века и отделившего в своих работах Сибирь от Центральной Азии. Данные воспоминания содержат описание Сибири, ее народов и дорог. Но в целом в конце XVII столетия европейцы знали о Сибири крайне мало.

Образы и стереотипы, возникшие в начале Нового времени в массовом сознании европейцев, приняли устойчивый характер и продолжили свое бытование в культуре Европы в XVIII - XX веках, а их отголоски обнаруживают себя вплоть до современности. Отмеченные образы достаточно ярко выражены в карикатурах, которые стали распространяться о России в европейской прессе XVIII - XIX и далее в XX веке. Изначально на Сибирь в данных изображениях акцент делался редко, однако общий набор узнаваемых «штампов» Российской Империи - мороз, медведи, бородатые мужики, цепи, агрессивные намерения и имперские амбиции, подавление свободы, ссылки, каторга и др., - оформился так, что их дальнейший перенос на Сибирь стал делом времени. Образы России средней полосы для таких «штампов» подходили менее, чем далекая и «дремучая» Сибирь.

В целом, в массовом сознании европейцев Сибирь, как правило, ассоциировалась с «азиатской колонией» России. Но, в отличие от 
«классических» заморских колоний, в Сибири отмечалось преобладание русского населения, соответственно Сибирь воспринималась как часть самой России, уходящая вглубь Азии. Это позволяет выявить самую главную специфическую сторону Сибири - в отличие от Европейских колоний, удаленных от метрополии, последняя была не совсем колонией, она являлась частью Империи, но слишком протяженной, дистанцированной, и потому воспринималась как несколько «другой мир». Отмеченную ситуацию можно сравнить с Аляской, которая став частью США, воспринимается американцами как часть территории государства, но достаточно отличающаяся и далекая от его более развитой части. В свою очередь в самой России Сибирь как колония не воспринималась [3, с. 766].

Показательно, что для многих европейских и американских путешественников и туристов, проникавших в Россию в XIX веке, территория до Урала представляла собой чтото безопасное и знакомое. Однако, двигаясь за пределы Урала, территория становилась «terra incognita», таинственной и опасной. В данном случае примечательны приводимые в статье Т. В. Грязнухиной и А. Б. Грязнухина воспоминания американского путешественника Джона Кэннана, который, описывая свой опыт посещения Сибири в конце XIX века, метафорически отмечает, что она представляет собой “округлое пространство с флагом европейской провинции”. Также Кэннан отмечает, что ни одна другая территория не вызывает столько любопытства у путешественников, прибывающих в Россию, как Сибирь. Однако данная территория по степени трудности выживания самая сложная в мире, и другой такой территории нет [5, p. 1462].

Отдельную грань рассматриваемой проблемы составляют представления европейцев о сугубо географических параметрах Сибири, которые были предложены географами XIX века. Дело в том, что Россия является страной с очень богатой и разнообразной природногеографической средой. Тем не менее, в ходе ее восприятия из-за рубежа отмеченное разнообразие несколько упрощается, опять же под влиянием обобщенных представлений о русской природе, с сопутствующими образами. Отмеченные образы активно тиражируются и внедряются в сознание потребителей на уровне медийной и особенно сувенирной продукции, позиционирующей в основном природу европейской части России (к примеру, Среднерусской возвышенности), а также при- роду русского леса. Причем, данная тенденция характерна для многих культур в ходе их взаимодействия. К примеру, для многих россиян природа Италии также может предстать в наборе обобщенных образов и «клише» итальянской природы и культуры. Данные представления могут не содержать разницы между природными и культурными особенностями Альпийской и Средиземноморской Италии, которые имеют существенные различия, очевидные для всех итальянцев.

Соответственно, аналогичное обобщение происходит и со многими культурами, обращающими свое внимание на Россию. Сибирь в таком случае достаточно трудно выявить и идентифицировать извне, она предстает как некая далекая, гигантская и загадочная территория, находящаяся где-то в глубине государства. Следствием такого неконкретного понимания Сибири становится масса допущений и искажений ее истинного облика в сознании европейцев, воспринимающих ее как своеобразный «бренд», наряду с такими презентабельными компонентами культуры России как Распутин, Екатерина II, казачество, шапкаушанка и т. д. Показательно, что в самой России некоторые из «брендов», имеющих для иностранцев существенное значение (например, Распутин), не играют столь важной роли. Тем не менее, тиражирование образов внутри России, которые ожидают увидеть зарубежные гости, во многом направлено на их стереотипизированные вкусы [1, с. 97].

В ряду различных образов Сибири выделяется также ее понимание как большого перекрестка исторических судеб разных народов, разных языков, легенд и шаманизма. В отмеченном плане показательно культурноантропологическое исследование о Сибири, созданное специалистом в области традиционных культур Арктики и Сибири Лучана Ваджи Саккоротти. В этом сочинении получает свое выражение некий «шарм», который оказывает «сибирский континент» на жителей Италии и других стран, выраженный в мистических и таинственных представлениях о нем. Сибирь в данной работе предстает как «Гигант», который «спит» на территории России, лежа от Урала до Тихого океана. В данной работе Сибирь воспринимается как место соединения Севера и Востока. Сибирская территория предстает как территория, где сосуществуют и сплетаются духовные характеристики, во многом типичные как для мифического Крайнего Севера, так и для Востока в его протяженности до Тихого океана. Данное обстоятельство де- 
лает «душу» Сибири уникальной и достаточно далекой от Западной цивилизации.

Как уже было отмечено, Сибирь привлекает не только интерес ученых, но также и обычных путешественников, оставивших немало воспоминаний о ней, которые в свою очередь повлияли на европейского читателя. Одним из таких путешественников является Даниэле Кастилиони из Ломбардии, автор двух книг и вместительных мемуаров, реалистично отражающих культуру Сибири, много лет посвятивший странствиям по ее дорогам. Кастилиони отмечает, что посещение Сибири стало для него уникальным опытом духовного развития. В своих работах автор указывает на невежество представлений по поводу данного региона России, бытующих на массовом уровне, начиная от самых простых образов и заканчивая максимально обобщенными представлениями о рассматриваемом регионе. Автор указывает на очевидность существования «двух сибирей» в европейском сознании реальной, настоящей Сибири и Сибири выдуманной. Однако, анализируя более-менее адекватные представления о сибирском регионе, путешественник отмечает, что и они ограничиваются в сознании западного человека главными путями коммуникации, например, сферой Транссиба. В свою очередь, другие территории Сибири (особенно северные) не получают должного внимания, например, Путорана. Также в данный ареал не всегда попадают ее южные территории, например, Алтай. Как следствие, относительно тех регионов Сибири, знание о которых носит не достаточный характер, начинают возникать и распространяться искаженные представления, вплоть до невероятных фантазий.

В настоящее время наиболее репрезентабельной сферой, в которой распространяются и преобразуются массовые представления европейцев о Сибири, является визуальная культура, содержащая целый спектр соответствующих образов.

В визуальном плане в первую очередь речь идет об этно-традиционных образах, составляющих богатство российского суперэтноca. Национальные жилища, фольклорные аспекты, верования, традиционные занятия и другие компоненты составляют основу данного «визуального ряда». Однако общей упорядоченности и ясного представления о том, где находятся территории распространения определенных этнических культур,-нет. Данная ситуация достаточно банальна. В этом случае справедливо указать на то, что мало кто из представителей неитальянской культуры сможет точно назвать все области Италии, включая порядок их расположения, с обозначением особенностей гражданской идентичности в каждом из регионов.

Одним из наиболее распространенных и устойчивых является уже отмеченный выше и достаточно релевантный образ Сибири как колоссально важного, богатого и экономически значимого региона. Другим стереотипом является представление об огромном векторе «расширения» России посредством «таинственного» Сибирского пространства, во многом сопряженного с Крайним Севером, но не имеющего четких географических очертаний в представлении европейцев.

Также необходимо указать на обобщенные представления европейцев о предыдущих этапах истории Сибири, вплоть до ее глубокой древности, включая историю до появления человека. В первую очередь, речь идет о геологических эпохах и различных отложениях, о динозаврах, «кладбищах мамонтов», неандертальцах, земле «постоянного выживания» предков «Homo Sapiens», сибирских ханствах, о «земле охотников» и т. д.

Сибирь для европейцев выступает своеобразным «источником богатства», причем не только материального, хотя с драгоценными металлами эта ассоциация достаточно крепкая. Сибирь - это «источник духовного богатства», там, в одиночестве человека и природы, возникают самые глубокие духовные качества охотников, рыбаков, старателей, постоянно рискующих и взаимодействующих с суровой реальностью. Такие качества достаточно соотносимы с качествами людей на Крайнем Севеpe, которые формирует его суровая среда.

Показательно, что для европейцев, несмотря на то, что Сибирь находится достаточно близко к Европе на уровне параллелей (речь о скандинавском регионе, Великобритании, части Германии, Польше и других странах), она часто воспринимается исключительно как часть севера. В данном случае речь не только о климатическом отнесении Сибири на север, но и о ее «переносе» на север географический в обыденных представлениях. Поэтому границы между Сибирью и Севером России (ее Арктикой) в сознании европейцев, по сути, размываются. Кроме того, Сибирь воспринимается как некое связующее пространство, как мост между Россией и Китаем.

С другой стороны, достаточно популярным образом Сибири за рубежом является ее восприятие как места каторги, депортации не- 
которых этносов, а также лагерей, включая криминальную составляющую. Примером распространения данных образов служит опубликованная во многих странах, в том числе и в Италии, книга Николая Лилина с соответствующим названием - «Educazione siberiana» («Сибирское воспитание», 2009). По мотивам данной книги, спустя четыре года после ее выхода, был снят одноименный фильм, пользовавшийся успехом.

Особую грань рассматриваемой проблемы представляет вопрос сибирской культурной идентичности, которую иностранцу выделить достаточно трудно. Дело в том, что при взгляде со стороны до сих пор открытым остается вопрос фиксации российской или постсоветской культурной идентичности как таковой, не говоря уже о ее региональных компонентах. В данном случае стоит указать, что многие аспекты культуры России в настоящее время воспринимаются из-за рубежа при сильном влиянии обобщенной советской компоненты.

Кроме того, рассматривая заявленную тему, необходимо указать, что многие стереотипизированные представления о Сибири получили свое распространение не только за пределами России, но и в ее культурном пространстве. Так, еще в начале XX века жители европейской России на уровне общих стереотипов имели преставления о Сибири как об огромном источнике ресурсов, но в плане культуры и экономического развития регион воспринимался как неразвитый $[5$, р. 1463]. В настоящее время отмеченный «образ» также находит свое проявление в массовой культуре.

В завершение отметим, что рассмотренная сфера обобщенных представлений о Сибири в культуре Европы хоть и выглядит как достаточно устойчивая, тем не менее, является пластичной и подвержена воздействиям, которые могут носить целенаправленный характер. С учетом возросшей роли визуальных коммуникаций и цифровых технологий в современном мире, представления о культуре его разных регионов, включая Сибирь, можно достаточно эффективно формировать, корректировать, но также и «искажать» их, внедрять в них соответствующие «инжекции». Вопрос в данном случае касается не только стихийных процессов, наблюдаемых в массовой культуре, но также и влияния многих сил, целью которых является формирование определенных массовых представлений о культуре той или иной страны или региона. Данное обстоятельство открывает перед гуманитарным знанием ряд возможностей и перспектив относительно рассматриваемой проблемы. Подобного рода «гуманитарные технологии», суть которых сводится к целенаправленному воздействию на сознание и поведение человека, необходимо изучать, вырабатывая механизмы противодействия явным «деформациям» образов определенных культур, а также разрабатывая технологии конструирования соответствующих представлений о культуре стран и регионов на уровне массового сознания в соответствии ценностями межкультурного диалога. Примером в данном случае может служить большой потенциал школьных курсов географии, истории и литературы, воздействие которых на формирование представлений о культурном пространстве определенных территорий достаточно велико [2, с. 104-105].

\section{Список литературы}

1. Леонов, И. В. Этно-традиционный сувенир в пространстве массовой культуры / И. В. Леонов, В. Л. Соловьёва // Вестник Санкт-Петербургского государственного института культуры. 2019. № 1. C. 93-98.

2. Леонов, И. В. Культурное пространство и основные пути его моделирования / И. В. Леонов, М. А. Харитонова // Человек. Культура. Образование. 2018. № 3. С. 100-115.

3. Bassin, M. Inventing Siberia: Visions of the

4. Russian East in the Early Nineteenth Century // The American historical review. 1991. Vol. 96, no. 3. Pp. 763-794.

5. Gruzdeva, A. S. An image of Siberia in Contemporary Foreign Photography (the 90s of the 20th Century-the First Decade of the 21th Century) // Journal of Siberian Federal University. Humanities \& Social Sciences. 2017. Vol. 10, no. 2. Pp. 255-270.

6. Gryaznuhina, T. V. Impact of Social Stereotypes on the Perception of Siberia by Inhabitants of European Russia in the 19th Century / T. V. Gryaznuhina, A. B. Gryaznuhin // Journal of Siberian Federal University. Humanities \& Social Sciences. 2013. Vol. 10, no. 6. Pp. 1461-1470.

7. Love, R. S. «A Passage to China»: A French Jesuit's Perceptions of Siberia in the 1680s // French Colonial History. 2003. Vol. 3: Idea and Action in French Colonization. Pp. 85-100. 
Daniele Lanza, Ph. D in Cultural Studies University of Turin (Turin, Italy) dnl.lanza@gmail.com

\title{
IMAGES OF SIBERIA IN EUROPEAN CULTURE
}

\begin{abstract}
The article analyses views on Siberia that had been spread in European culture of the 18th 21 st centuries; describes the key political, ideological, and economic factors that had effect on forming and strengthening of such views in cultural consciousness of a historical and the today's European. Little-known for the Russian historiography parts of memoire and ethnographic literature written by foreigners who had personally visited Siberian territories are given. The author's view on genesis of true and false historical, cultural, and geographical stereotypes about Siberia is outlined.
\end{abstract}

Keywords: Europeans' views on Siberia, cultural stereotypes about Siberia, foreign travelers' memoires about Siberia, European press about Siberia, Siberia as a Russian cultural brand, mass culture, mass consciousness, Siberia, Altai, Europa, European culture, an image in culture, a cultural stereotype.

\section{References}

1. Leonov, I. V. Etno-tradicionnyj suvenir v prostranstve massovoj kul'tury [Ethnotraditional Souvenir in Mass Culture] / I. V. Leonov, V. L. Solov'yova // Vestnik Sankt-Peterburgskogo gosudarstvennogo instituta kul'tury [Bulletin of Sain Petersburg State Institute of Culture]. 2019. No. 1. Pp. 93-98. [In Russ.].

2. Leonov, I. V. Kul'turnoe prostranstvo i osnovnye puti ego modelirova-niya [Cultural Space and The Main Ways to Modelling It] / I. V. Leonov, M. A. Haritonova // Chelovek. Kul'tura. Obrazovanie [Human. Culture. Education]. 2018. No. 3. Pp. 100-115. [In Russ.].

3. Bassin M. Inventing Siberia: Visions of the Russian East in the Early Nineteenth Century // The American historical review. 1991. Vol. 96, no. 3. Pp. 763-794.

УДК 316.347:008:745/749

DOI: 10.32340/2514-772X-2019-1-82-87
4. Gruzdeva A. S. An image of Siberia in Contemporary Foreign Photography (the 90s of the $20^{\text {th }}$ Century-the First Decade of the $21^{\text {th }}$ Century) // Journal of Siberian Federal University. Humanities \& Social Sciences. 2017. Vol. 10, no. 2. Pp. 255270.

5. Gryaznuhina, T. V. Impact of Social Stereotypes on the Perception of Siberia by Inhabitants of European Russia in the $19^{\text {th }}$ Century / T. V. Gryaznuhina, A. B. Gryaznuhin // Journal of Siberian Federal University. Humanities \& Social Sciences. 2013. Vol. 10, no. 6. Pp. 1461-1470.

6. Love R.S. «A Passage to China»: A French Jesuit's Perceptions of Siberia in the 1680s // French Colonial History. 2003. Vol. 3: Idea and Action in French Colonization. Pp. 85-100.

\section{Санкт-Петербургский государственный институт культуры, Государственный литературно-мемориальный музей Анны Ахматовой в Фонтанном Доме (Санкт-Петербург, Россия) ivaleon@mail.ru}

И. В. Леонов, доктор культурологии,

\section{РЕПРЕЗЕНТАЦИИ ТРАДИЦИОННЫХ КУЛЬТУР В ИНДУСТРИИ СУВЕНИРОВ}

Аннотация. Представлен анализ современного состояния и основных направлений развития современной отечественной индустрии этно-традиционных и историко-культурных сувениров. Рассмотрен феномен зависимости ассортимента сувенирной продукции от степени устойчивости стереотипов в массовом культурном сознании в отношении исторической и современной России, отдельных историко-культурных зон страны. Охарактеризован эффект влияния художественно-эстетического облика сувенирной продукции на формирование представлений потребителей о культурных особенностях народов, населяющих современное российское государство. Затронут вопрос о допустимых пределах «искажений» отечественных историко-культурных реалий, возникающих из-за присутствия на рыке некачественных этно-традиционных сувениров.

Ключевые слова: сувенир, артефакт, индустрии культуры, историко-культурный процесс, визуальный образ, гуманитарные технологии, репрезентация традииионной культуры, историкокультурная репрезентативность сувенира. 